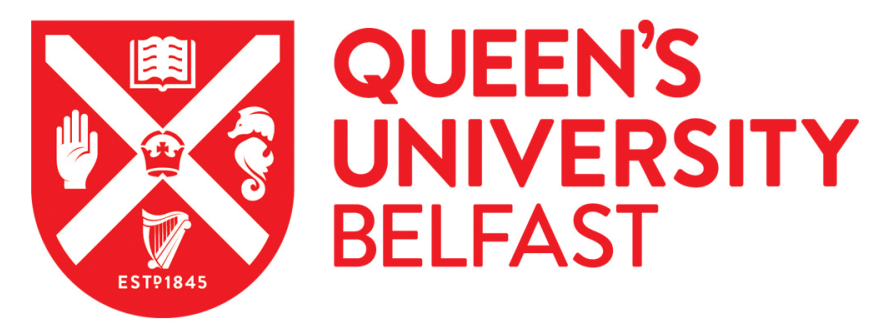

\title{
Interpretations of national identity in post-conflict Northern Ireland: A comparison of different school settings
}

Furey, A., Donnelly, C., Hughes, J., \& Blaylock, D. (2016). Interpretations of national identity in post-conflict Northern Ireland: A comparison of different school settings. Research Papers in Education, 32(2), 137. https://doi.org/10.1080/02671522.2016.1158855

Published in:

Research Papers in Education

Document Version:

Peer reviewed version

Queen's University Belfast - Research Portal:

Link to publication record in Queen's University Belfast Research Portal

Publisher rights

(C) 2016 Informa UK Limited, trading as Taylor \& Francis Group

This is an Accepted Manuscript of an article published by Taylor \& Francis in Research Papers in Education on 28 Mar 2016, available online: http://www.tandfonline.com/doi/full/10.1080/02671522.2016.1158855

\section{General rights}

Copyright for the publications made accessible via the Queen's University Belfast Research Portal is retained by the author(s) and / or other copyright owners and it is a condition of accessing these publications that users recognise and abide by the legal requirements associated with these rights.

Take down policy

The Research Portal is Queen's institutional repository that provides access to Queen's research output. Every effort has been made to ensure that content in the Research Portal does not infringe any person's rights, or applicable UK laws. If you discover content in the Research Portal that you believe breaches copyright or violates any law, please contact openaccess@qub.ac.uk. 
Interpretations of National Identity in Post-Conflict Northern Ireland: A Comparison of Different School Settings

Andrea Furey (Ulster University), Joanne Hughes (Queens University), Caitlin Donnelly (Queen's University), Danielle Blaylock (Queen's University)

Address correspondence to Andrea Furey, School of Psychology, Ulster University, Magee Campus, Northern Ireland, BT48 7JL, UK. Email: a.furey@ulster.ac.uk 


\section{Abstract}

It is generally accepted that education has a significant role to play in any society transitioning from conflict to a more peaceful dispensation. Indeed, some have argued that the education system potentially represents the single most effective agent of social change with the capacity to bridge ethnic division in conflict affected countries. Despite the potential, educational policy makers grapple with the dilemma as to precisely how school systems can best facilitate this agenda. This paper thus attempts to shed light upon the dilemma by exploring pupil identity and associated intergroup attitudes across various school types in Northern Ireland. Five schools were selected for the study with each one representing a particular sector within the Northern Irish education system (maintained grammar, maintained secondary, controlled grammar, controlled secondary, integrated). This led to a total sample size of 265 pupils. The main findings show that children across separate Catholic, separate Protestant, and mixed Catholic and Protestant educational contexts construct and interpret identity differently. At the same time, our data suggests that no one school setting has supremacy in promoting social cohesion. The implications of these findings are discussed.

Keywords

Integrated education, separate education, identity, intergroup attitudes

\section{Introduction}


The relationship between schools and society has long been a matter of interest to religious authorities, academics and policy makers; schools represent important sites for presenting, reflecting and reproducing societal values and as Durkheim argues are '...the only means by which society prepares within the children the essential conditions of its very existence' (1956:71). The socially transformative potential of schools has also been recognised in law and policy. Thus the UK Race Relations Amendment Act (2000) stated that educational institutions should seek (a) to eliminate unlawful racial discrimination; and (b) to promote equality of opportunity and good relations between persons of different racial groups. Moreover, the Department for Education in England has also made clear that 'every state-funded school must offer a curriculum which: promotes the spiritual, moral, cultural, mental and physical development of pupils at the school and of society' (Statutory guidance national curriculum in England: framework for Key stages 14)

Whilst these are clearly laudable objectives, recent research evidence is conflicted as to the type of school that might be best placed to realise them. For some the mixed ethnic/religious school represents the best site for challenging discrimination and fostering good relations between different and divided groups (Strike, 2001). Framing his argument in economic terms, Judge attests to the problems that separate faith based education creates and uses examples from Northern Ireland to substantiate his analysis:

Faith-based schooling quite obviously did not of itself manufacture the tragic divisions of that society [Northern Ireland]: but nobody has yet argued that it has in any sense helped or is helping to heal them (Judge, 2001:471) 
Although financial considerations are clearly important, the issue is necessarily more complex and as Pring (2005) argues, is fundamentally related to the aims of education. Thus the purpose of schooling in any liberal democracy ought not to be to cultivate a faith but rather to promote autonomy, and schools seeking to cultivate a faith can be inimical to the values of social cohesion. Doubt has however been cast on this analysis. Levinson (2007) for example has explained that it is by no means clear that the practices endorsed in the common school will necessarily challenge discrimination or division, not least because although there may be a balance of different groups represented and an official commitment to multi-culturalism, the students may not be adequately prepared to understand the views, traditions and perspectives of others. She argues that separate schools may therefore offer as good a context for creating positive intergroup relations as multi-cultural schools. This point has been clarified by Halstead and McLaughlin (2005) who make explicit links between the positive sense of identity that is fostered in the separate school and pupil tolerance. The cogency of their arguments however belies the lack of empirical research in the field and since Grace has outlined the case for further analysis of the contribution of [faith] schools to social cohesion in 2005, the dearth remains. This paper is an attempt to address this gap by exploring pupil identity across different school types in Northern Ireland. Northern Ireland offers a particularly pertinent site for the exploration of such issues because since the inception of the state Catholic-nationalists and Protestant-unionists have generally been educated in separate schools and the links between the school system and the political conflict have prompted debates resonant of that outlined above. Yet, and importantly, despite the assumption that different school types can shape identity or contribute to division or cohesion, little is understood of their role in this regard. The paper begins with a brief description of the 
education system in Northern Ireland before moving on to explore the concept of identity. The qualitative methods are explained before the presentation of data.

\section{$\underline{\text { Schools and Identity in Northern Ireland }}$}

Nowhere in Northern Ireland is the division between the two communities more apparent than in the education system. Despite attempts by the first Education Minister Lord Londonderry to establish a non-denominational secular system of education in 1923 'where children of different faiths might study and play together' (Buckland, 1979:250) pressures from the churches, particularly the Protestant churches, ensured that the 1930 Education Act provided for a separate school system for Catholics and Protestants (Akenson, 1973) that remains today. Importantly, the schools are not recognised only as institutions that transmit a set of religious beliefs rather, they each reflect and reinforce a set of values that are resonant with either a British or Irish cultural identity and it is this, combined with the commitment to a separate religious doctrine, that sets them apart (Murray, 1985).

Such was the strength of loyalty to the separate school system that calls for an integrated system of education were not widely rehearsed until the outbreak of violence in the early 1970s when attention began to be directed towards the school system as a possible cause of social and political dissonance (Dunn and Morgan 1999). Thus, and in response to these concerns, a charitable group, All Children Together, was established in 1974. This organisation lobbied for the establishment of new integrated schools where children from different communities would be educated together. Support for the concept of integrated education grew throughout the 1970s and in 1981 the first integrated school, Lagan College, was established as an independent institution. Throughout the 1980s a 
further three schools were established and in 1989 the Government agreed to fund the schools and to 'facilitate and encourage' the further development of new integrated schools or to permit existing schools to legally transform to 'controlled integrated' status. The schools are Christian in ethos and explicitly strive towards a religiously balanced pupil enrolment, teaching staff and governing body.

Yet and despite their intuitive appeal, the development of integrated schools has largely stalled in recent years. At present integrated schools educate just $7 \%$ of the school age population and their slow development has prompted the Catholic Council for Maintained Schools, the managing authority for Catholic schools in Northern Ireland, to call for a review of the Department of Education's duty to encourage and facilitate integrated education (Irish News November 2014). The tensions that are reflected in the CCMS request are ostensibly economically derived: research on the rationalisation of the schools' estate showed a surplus of school places in Northern Ireland and suggested that efforts should be made to amalgamate or close schools with small numbers (Bain, 2006). It might be argued that there is little need to extend the numbers of schools when there are clearly excess places in existing schools. However, the issues raised also have a broader resonance with debates on identity and schooling that this paper wishes to explore. So whilst fears that the integrated school sector is unnecessarily absorbing funding that might usefully be directed towards the existing school types is a valid concern, the threats posed by an integrated system of schooling are inevitably more than just financial: creating spaces wherein groups meet and are taught by those from different backgrounds has the potential to imperil the sustainability of the traditional identity categories [upon which the separate school system depends] by creating a space for their possible re-negotiation. 
Some research seemingly confirms this possibility. Hayes et al (2007) for example showed that adults who had experienced an integrated education were choosing the identity category of 'Northern Irish' to define themselves, thus representing a possible mutation of traditional identity classifications. The question of identity construction and maintenance in different school settings is at the heart of this paper. In essence, we seek to explore how Catholic and Protestant pupils attending different school types conceptualize their identity and relate to the 'other' group on the basis of their own and ascribed identities. We are particularly interested in the inter-play between religious, cultural and national identity categorisation and the implications for inter-group relations. Before presenting the empirical data, we outline a theoretical overview of social identity theory.

\section{Identity: a theoretical analysis}

Theoretical explanations for conflict between different groups in socially stratified societies, although multifaceted, are predominantly underpinned by Social Identity Theory (SIT) (Cairns, 1982; Trew \& Benson, 1996). According to this theory, identity emanates from an awareness of membership to a social group, combined with the subjective interpretation of that membership in relation to value and emotional significance (Tajfel, 1978). Thus, within this framework, identity is viewed as encompassing three distinct dimensions. The first dimension, which is cognitive in nature, refers to self-categorization or identification of oneself as a member of a certain social group. However, self-categorization and differentiation between groups does not necessarily produce social identification. Rather the subsequent development of a social 
identity is determined by the extent to which the in-group has been integrated into the sense of self and the self is experienced as an integral part of the in-group.

Secondly, there is an evaluative dimension such as the value individuals attach to group membership. A basic tenet of the theory is that individuals engage in biased intergroup comparisons in order to view one's in-group and one's self positively. The third dimension refers to the extent one feels emotionally involved within a given group. This dimension has been termed 'affective commitment' and is considered an important determinant of behaviour. Clearly, individuals are differentially concerned with the significance that they attach to group membership (Doosje \& Ellemers, 1997). Therefore, the degree of commitment to a social group is important, not only in predicting the extent to which individuals will act on behalf of their group but also in assessing the power of the group to influence the individual (Jackson, 1981). Concomitant with group membership, there are often standards and perspectives against which behaviours and opinions are evaluated. An individual's commitment is an important determinant of the extent to which these perspectives and norms of the groups become internalized and cause people to behave and define themselves in terms of group norms.

More recent research has further argued the need to view identity within a multidimensional framework and likewise has attempted to establish independent dimensions of identification. For example, Ashmore, Deaux and McLaughlin (2004) identified a number of key elements in identification including self-categorisation, evaluation, importance, attachment, content and meaning, behavioural involvement, and social embeddedness. Many of these dimensions are consistent with those contained within the original SIT framework, with the remainder reflecting a consequence of 
identity. The dimensions described above are believed to be especially crucial in situations like Northern Ireland where, membership of the two main identity groups is virtually inescapable and group boundaries are relatively impermeable. Under these circumstances, the orientation of an individual to his / her in-group typically involves some simultaneous psychological relationship to the out-group (Mummendey et al., 2001).

At the same time, one of the main attractions of SIT is its acknowledgement that identities are by no means static. Rather the need for, and expression of social identities involve a series of complex and dynamic processes. People simultaneously identify with numerous social groups. Consequently, different identities are activated and take precedence at different points in time. The particular identity, which takes precedence at any given time, is thought to depend upon the situation or social context an individual finds himself / herself in. Hence, social identities are situationally determined or contextually based. More specifically, 'different situations tend to 'switch on' different conceptions of self so that social stimuli are construed and social behaviour controlled in the appropriately adaptive manner' (Turner, 1982, p. 20). Deaux (1996) goes so far as to suggest that social identity is entirely dependent upon social context and argues that changes in identity are directly attributable to the distribution of people and characteristics within a particular environment.

This variable nature of identity is thought to be particularly intriguing when considering ascribed social identities such as nationality and ethnicity. In contrast to achieved social identities for example, ascribed identities are believed to be relatively enduring. The dependence of national and ethnic identity on social context has raised important 
questions regarding what precisely happens to identity when contexts change. Social identity and self-categorisation theory both posit that group identification increases under situations when contextual change increases the salience of an identity (Emler \& Hopkins, 1990; Waddell \& Cairns, 1986). Longitudinal research (Ethier \& Deaux, 1994) supports this assertion but only for those whose identity is strong in the first place.

Only a limited number of studies exist which have specifically sought to examine the effects of situations on social identity. Notable exceptions in Northern Ireland include research carried out by Waddell (1988) and Waddell and Cairns (1986). Working within the framework of SIT, these researchers examined the effects of situations on the salience of ethno-political identities in Northern Ireland. However, for the most part, the results of this research indicated little evidence of situational variability in the Northern Irish population. Waddell and Cairns (1986) attributed these results to the salience of social identity in conflictual societies.

Taking account of the theory discussed above, and adopting a qualitative approach, we set out to explore the concept of identity in schoolchildren in Northern Ireland. Consistent with the literature, we make a distinction between identification of and identification with, and focus upon analysing the underlying subtleties intrinsic to interpretations of identity. We do this within two unique situational contexts; Northern Ireland's post conflict transitional status and the different school settings within Northern Ireland.

\section{Method}


The current study adopted a qualitative approach and required that children write an essay entitled 'My Country'. Embodying the assumption that there are multiple realties that are socially defined, qualitative methods are invaluable in producing rich culturally specific data (Firestone, 1987), and thus highly suited to research on identity and associated processes. [Essay] writing is an especially popular qualitative technique for research and is typically promoted on several grounds: Alternative techniques such as one-to-one interviews may not allow researchers access to the deeper perspectives on contentious issues, a point well illustrated in the work of Elizabeth (2008) who argues that participants' willingness to disclose personal matters can be enhanced when they are granted the anonymity and confidentiality that is afforded through writing. Whilst cognizant of the limitations of such an approach and appreciative that writing cannot replace the exposition that would naturally emerge during interview, the unobtrusive nature of the method meant that we were better placed to secure access to large numbers of students across a range of school types. In addition, and of importance, the technique has already been used in Northern Ireland where the results offered important insights into the processes and dynamics of conflict (Muldoon, 2007).

\section{Sample}

Five schools were selected for the study with each one representing a particular sector within the Northern Irish education system (controlled (predominantly Protestant) grammar and secondary, maintained (predominantly Catholic) grammar and secondary, integrated (mixed intake)). As a result of this selection method, each individual school is located within a unique demographic environment and no attempt will therefore be made to generalize from the data. Information pertaining to each demographic environment was accessed via the 2011 census, using school postcodes to identify a specific ward area. 
The first school, A, is a Catholic maintained girls secondary school situated in Town A. $92 \%$ of the population in the area in which School A is located are Catholic and most identify themselves as Irish [58\%); 24\% identify as Northern Irish and British (11\%) (2011 Census); School, B, is a Catholic boy's grammar, situated in Town A. $88 \%$ of the population in the area where the school is located is Catholic. The majority identify themselves as Irish (54\%), followed by Northern Irish (30\%), and British (13\%). The wards in which both these schools are located fall within the top $20 \%$ of deprived wards in Northern Ireland. In addition, the larger district in which they are both situated was badly affected during the conflict (Fay et al., 1999). School C, is a controlled [protestant] secondary school situated in Town B. $80 \%$ of the population of the area in which the school is located is Protestant. The majority identify themselves as British (78\%), followed by Northern Irish (32\%), and Irish (5\%). The area has experienced a relatively low level of sectarian conflict (CRC, 2005) and deprivation. School D, is a controlled grammar situated in Town C. The population of the area where school D is located is comprised of 58\% Catholic and 37\% Protestant. In terms of identity, 38\% classify themselves as British, followed by $32 \%$ as Irish, and 29\% Northern Irish. The last school, E, is an integrated school situated in Town D. In terms of the religious breakdown there are $23 \%$ Catholic and $72 \%$ Protestant. The majority identify as British (63\%), followed by Northern Irish (27\%), and Irish (11\%).

Each of the schools was selected in so far as they provided a micro-representation of the wider Northern Irish education system. This approach necessarily frustrated attempts to achieve socio-demographic parallelism between the schools. For example, the majority of Catholic maintained schools are single sex whereas both Protestant controlled and integrated schools are mixed sex. Nevertheless, previous research has found gender to have a minimal 
impact upon identification processes (Trew, Cox \& Ward, 1995; Fahey, Hayes \& Sinnott, 2005). However, social class disparities among the different school settings are potentially more admissible. Reflective of wider societal disparities, the two Catholic schools are from more deprived areas compared with the other schools in our research. This imbalance underscores the complexity of the relationship between social class and identity in Northern Ireland. Within the context of this research, it was impossible to disentangle the interactive effects of these variables. Nevertheless, while acknowledging this social class variance, previous studies consistently demonstrate community background as by far the strongest predictor of patterns of identification (Bull, 2006).

Data were collected in the winter of 2012/ 2013, with year 13 pupils (aged 16 to 17) from each of the schools referred to above. This led to a total sample size of 265 pupils, of which $45 \%$ were Catholic and 36\% were Protestant. See Table 1 for the breakdown of participants according to school type.

Insert Table 1 about here

\section{Data Analysis Procedures}

The data were analysed using the Constant Comparative Method (Glaser \& Strauss, 1967) described by Maykut \& Morehouse (1994). This allowed the centrality and significance of particular themes to be identified. The analytical process comprised four distinct stages. The first involved inductive category coding based on 'units of meaning' of textual data, and the simultaneous comparing of these units across categories (Goetz \& LeCompte 
(1981). After an initial review of the essays, primary patterns in the data were identified and categorized (Patton, 1990). This preliminary categorization is accompanied by a comparison of all similarities and differences between categories. The second stage of analysis involves the continuous refinement of categories. Here, we defined and redefined categories by establishing and modifying the criteria used for assigning them to the data (Dey, 1993). Following this categorization process, the relationships and patterns across groupings were explored. This facilitated the final stage of analysis which involved integrating the data to produce an understanding of the people and setting being studied (Maykut \& Morehouse, 1994).

\section{Reflexivity}

The close relationship between researcher and participant in qualitative research has been well documented: there is it is argued a need for researchers to pay attention to the ways in which their own values and beliefs shape the research process. Yet the tendency for researchers to present themselves as 'neutral' has been noted, particularly in Northern Ireland where, as Finlay (2001) has argued, researchers often seek to maintain a distance from their own emotional involvement in the conflict. As three of the authors grew up in Northern Ireland, one is Catholic, one is Protestant and the other was brought up in a mixed religious family, we do not argue that we are neutral. Indeed the process of collecting and analyzing the data brought to the fore our own perspectives and views on identity within the context of Northern Ireland and the analysis in particular created a space for us to challenge some of our own deeply held assumptions pertaining to our own identity and the school system in Northern Ireland. Our mixed backgrounds we believe allowed for a more nuanced and discursive approach to the analysis than may have been afforded had we all been drawn from the same identity categories. It was thus 
through a process of consensual validation, all four researchers agreed on the final categories and overarching themes (Muldoon et al., 2007).

\section{Findings}

We present the results in the order of the four most consistent and relevant categories for our research aim: identification; content and meaning associated with identity, including evaluation and cultural and emotional attachment; contextual variation in identity; and consequent intergroup attitudes and relations. In each instance, we also any report observed disparities between the different school settings.

\section{Identification}

Consistent with previous research indicating the significance of national identity, our findings suggest that self-categorisation remains an important feature for young people in Northern Ireland. Along this dimension, within the entire sample, 243 respondents self-identified as Irish, British, or Northern Irish. In the separate schools, specific patterns of responding primarily emulated traditional divisions in national identity. For example, in responses from the two Catholic schools (A and B), identification is overwhelmingly Irish (64\%) albeit with a small proportion opting for Northern Irish (27\%). In contrast but predictably, the respondents from schools C and D (Protestant schools) principally claim either Northern Irish (58\%) or British identity (34\%). Not surprisingly, we found greater variation in national identity within the integrated school context (school E). Here, the majority (44\%) adopt the Northern Irish identity, although a sizeable proportion also self-categorise as Irish (31\%) and British (16\%). Self-categorisation is undoubtedly the most salient aspect of social identity. However, this perceptual aspect describes only the cognitive perception of group membership (Gould, 1975). 


\section{Content and Meaning}

Embedded within categorical group membership are a set of related interpretations and affect (Ashmore et al., 2004). With respect to the former, our data reflects distinct cultural connotations associated with respective identities. In school A and B, where Irish identity is predominant, the majority of participants (54\%) refer to an array of cultural traditions that permeate 'Irishness'. These include linguistic heritage, mythology, traditional music and dance, Gaelic sport, and the Tricolour. Taken together, these aspects of cultural heritage represent a significant source of national pride for Catholics. This finding corresponds with research indicating a high correlation between identity and in-group pride, with the former significantly predictive of the latter (Jackson \& Smith, 1999). The value attached to Irish identity by one Catholic pupil is encapsulated in the following;

For me, my country is what forms my life. I am proud to be Irish from Gaelic sports to Irish music; almost everything about this country is unique. Our own native language. This conveys the pride of the Irish people and symbolizes the desire of the people to carry on tradition and be proud to be Irish. Everyone loves the Irish. I see Ireland as one country (Irish Catholic, School B).

In contrast to the Irish identity, both the British and Northern Irish identity, mainly adopted by Protestant participants in school C and D, appear less imbued with cultural significance. Among those categorizing themselves on this basis, culture is more subtly alluded to in the context of British symbolism, Loyalist parades, and the Northern Irish football team. Our data demonstrates fragility surrounding these two identities, and reveals elements of defensiveness pertaining to cultural identity. This defensiveness, 
although manifest in assessment of various political issues, is especially evident in response to the recent controversy around the decision to restrict the flying of the Union flag over Belfast City Hall.

To me, my country is my identity. My country gives me a place where I feel I belong and it makes me feel proud. It sickens me to think that people would want to take my pride away from me. That is why the flag issue over Belfast City Hall has raised many concerns. Although violence is not the answer, I know how the protesters feel. The Union flag has become a symbol of their culture and they feel that their culture is being suppressed (British Protestant, School D).

This extract resonates strongly with other research which suggests a shift in the identity of Protestants in Northern Ireland. Finlay (2001, p.3) argues that Protestant identity, once based upon rationalism and triumphalism, is now perceived 'in terms of tradition, defeat and associated emotions such as alienation, fatalism, and resentment'. Importantly however, he maintains that current Protestant defeatism is more a reflection of the absence of a meaningful cultural identity in Northern Ireland than the by-product of a pre-existing identity. This is something that has also been picked up by Cassidy and Trew (2004) who have argued that for Protestants, national identity is lower in salience compared with Catholic identity (Cassidy \& Trew, 2004). So whilst it was argued earlier that the 'Northern Irish', identity category can present an alternative to traditional oppositional identities (Muldoon et al., 2007) our data suggested that the Northern Irish identity appears to be associated with the same sense of insecurity and alienation among Protestant participants as the British identity. 
Yet what is perhaps more important for this paper is that the data indicates an observable contrast between the meaning attached to 'Northern Irish' by protestants in the controlled schools and participants in the integrated school (school E). In school E, where most categorize themselves as Northern Irish, essays are characterized by a deliberation of the complexities surrounding identification in Northern Ireland. This is the case for both Catholic and Protestant participants:

I always wonder if I should answer by saying Ireland, the land where I live, or Britain, the Government that rules where I live. It seems that in Northern Ireland if you call yourself Irish then you are automatically thought to be a Catholic / British - Protestant. It is due to this judgmental factor that I hate saying my nationality (Northern Irish Catholic, school E).

My country is Northern Ireland and I see it as part of the UK and not Ireland. I acknowledge this because their government is different and they don't use the same currency. My country doesn't mean a lot to me because of all the stuff that's happened in the past. You could nearly say I'm ashamed to live in Northern Ireland (Northern Irish Protestant, school E).

Here, adopted identities are rationalized, and at the same time, alternative identities are acknowledged, suggesting a pattern of bilateral acceptance. This finding, unique to school E, lends support to research cited earlier relating to the tolerance of different identities that can be fostered in integrated school contexts (Judge, 2001; Strike, 2010). In school E, expressions of culture underpinning respective identities seem to be evaluated less positively than in the separate schools. Rather than being viewed as a source of pride, they are typically seen as fundamental to separatism and division. For 
example, reference is made to how different sports constitute representations of identity, and the polarizing effect this has on community relations. The contrast in perspectives between school $\mathrm{E}$ and the separate schools in regard to cultural expression is perhaps best highlighted by comments pertaining to the issue of flags. Unlike their counterparts in school C and D, who view recent Belfast Council decisions to restrict the flying of the Union flag in Belfast as offensive to their identity, Protestant participants in school E showed more conciliatory attitudes:

My opinion of the flying of the flags in Belfast is that it's stupid. Don't see why people get so annoyed about it. There should be both flags or none. An even better idea is to make a new flag that represents Northern Ireland on its own and accepting both countries (Northern Irish Protestant, school E).

Thus, a pervasive finding among both groups in school $\mathrm{E}$ is the willingness and desire to evaluate and ameliorate cultural sources of contention. This may be a consequence of the contact between the groups and the mission of the schools which explicitly seek to foster in participants a perspective taking approach to controversial identity issues. (McGlynn, Niens, Cairns \& Hewstone, 2004). It may also of course suggest that those who choose integrated schools are already more positively disposed towards the 'other' at the outset and this is why they are drawn to this school type [Dunn and Morgan, 1999). Our data suggest that the different patterns of identification discussed above have a subsequent differential impact on individuals' attachment or commitment to identity. The findings also reflect psychological literature that argues a distinction between two forms of identity commitment; interactional and affective. Within the literature, the former is described in terms of the social relationships associated with a particular identity (Stryker \& Serpe, 1982; Cassidy \& Trew, 1998). This aspect of commitment is easily 
detectable throughout the essays and typically reflected in statements outlining the significance of community, friends, and family.

My country has become my life and culture. Everything I do fits in and is because of my country and my upbringing in this country. A reason I love this country is because of people and their hospitably. Especially in my local area, everybody knows each other and there is a great sense of community spirit (Irish Catholic, school B).

My country means a lot to me as me, my friends, and family are raised in Northern Ireland. I feel I'm dedicated to live my life in Northern Ireland as King Billy fought for ones right to live our lives in Northern Ireland (British Protestant, school C).

These extracts suggest that regardless of identity persuasion, Catholics and Protestants seem committed to their respective identities, and this commitment is justified by associated attachment with familial and community networks. Justification is most marked among Protestant participants in school C and D which is surprising in so far as previous research in Northern Ireland (Cassidy \& Trew, 2004) has found interactional commitment more important among the Catholic community. Again, interesting differences emerge when considering the comments within the integrated school setting. Here, less emphasis is placed upon interactional commitment. On occasions, choice of identity is explained on a trans-generational basis but at the same time, there is greater self-awareness and recognition of the potential bias associated with this method of identification. As one British Protestant participant commented, 'I have never seen my culture as sectarian but I do believe my view will be biased'. Significantly, transgenerational transfer of identity does not seem to translate into unequivocal attachment 
to traditional social networks. Rather, this subgroup is quick to criticize any community, peer group, and friendship affiliations adopting a single restrictive identity outlook. Indeed, our data reveals discussion that highlights how linkages to former friendships are fractured as a result of insular perspectives to identity. This is encapsulated in the following statement which suggests that interactional commitment, a prominent aspect of identity within the separate schools, is less important within the integrated context:

When I joined the secondary school (integrated), it was soon clear that religion doesn't matter in the slightest. I split up with my friends. They all went to a Protestant secondary school. I will still stay in contact with them. They are still my friends but the one thing I hate about them is that I have never heard the word Catholic from them. It has always been Fenion (derogatory term for Catholics). I hate that word (British Protestant, School E).

The data also indicate that affective commitment is an important aspect of the respective identities although in contrast to interactional commitment, it seems to be infused with complexity. Typically described as 'emotional attachment to group membership, affective commitment is often viewed as reflecting the two positive fundamental emotional categories of joy and love (Shaver, Schwartz, Kirson \& O'Connor, 1987). Shaver et al. (1987) define joy as happiness arising from the in-group as a social category and define love as the emotional attraction or affection towards the group as a social category. Affective commitment is evidenced here in the expression of positive emotions induced by identity. Participants frequently refer to feelings of joy and love associated with identification although such references are more pronounced among participants in the first four schools. However, at the same time, there are observable differences between the Catholic and Protestant schools in that identity associated emotions appear more 
mixed among the Protestant students (school C and D). This may suggest that affective commitment is lower among the Protestant community.

Notwithstanding observed emotional expressions of identity, explicit statements pertaining to identity commitment or attachment are less common. Furthermore, as with interactional commitment, disparities in affective commitment emerge when comparing participants in the separate and integrated contexts. Within the integrated school, participants convey the impression of emotional detachment from traditional identity patterns. This detachment is consistently explained on the basis of the ongoing political violence, segregation, and discrimination throughout Northern Ireland, and equally applicable to both Protestants and Catholics. The following statements reflect this tendency:

Don't have strong positive feelings towards my country. No emotional attachment to Northern Ireland at all. Only attraction is family. The lack of unity or the attitude of separation and segregation that I see every day makes me feel this way (Northern Irish, no religion, School E).

My country is Northern Ireland....Doesn't mean that much to me. All that comes to mind is violence, paramilitary groups, the troubles and sectarianism. So to me, Northern Ireland is nothing special (Northern Irish Protestant, School E).

The finding that those in the integrated school context are readily able to disengage from the emotional elements of associated identities is perhaps unsurprising and arguably, it may be an expected consequence of defining identity is less exclusive terms. This view is substantiated in the literature where, it is argued, affective commitment varies as 
function of strength of initial identification (Ellemers, Kortekaas \& Ouwerkerk, 1999). However what is perhaps particularly interesting and as will be shown below whilst this more inclusive conceptualization of identity seemed to suggest that students were less concerned with the traditional basis of conflict, they seemed to be positioned more negatively towards those who did not share their more 'moderate' views:

\section{Attitudes to the 'other' identity}

Thus far, the data indicate a marked contrast between the separate and integrated schools in relation to identity and its associated dimensions. When exploring the attitudes to the 'other' this too appears best explained on a separate versus integrated school basis. Within the four separate schools, many participants (31\%) discussed the conflict in terms of having a negative impact upon their country. Although condemning of violence, most attributed the blame for the conflict on 'the other community'.

People in this country still endure a lot with sectarian abuse and security forces/IRA. [The] Country is not perfect with riots going on from June to September with the stupid marching season and the disrespecting of Catholics and their traditions and culture (Irish Catholic, School B).

The history of my country back 20 years ago was rough and violent. Many people died for nothing. IRA was at the heart of this war causing the upheaval (Northern Irish Protestant, School D).

In contrast however students in the integrated school were more likely to write disparagingly of 'one-sided' view points and to argue for legitimacy to be accorded to all perspectives relating to the NI conflict. The following was typical: 
It's fine to have opinions but I don't think they should be so one-sided (Northern Irish, no religion, School E).

Moreover, and echoing the views of Judge and Strike earlier, participants attributed their more moderate perspectives to the integrated school context. Thus they explained that their school environment was critical to the fostering of tolerance and respect towards the 'other' and importantly that a lack of integration can serve as a catalyst for the conflict:

If everyone was integrated, maybe things wouldn't be so bad? I respect that however, I also understand how and why there is conflict in Northern Ireland. The main reason I believe is that conflict exists because people don't understand other cultures and when people don't understand something, they lash out (Northern Irish Protestant, School E).

The hostilities between the groups were deemed shameful and there was a notable effort to condemn intergroup hostility:

I will never deny that I'm Northern Irish although I'm still ashamed to be from this country. There are very few people here with some sort of intelligence. Most are brainwashed, and as a result of not being able to think for themselves, most are stupid. My country is violent and sectarian. Another example to the world that religion can truly screw things up. To make it worse, Catholics and Protestants are virtually identical. Northern Ireland will just get worse. Paramilitaries are 
starting to stir up again. I hate my country and can't wait to get out (Northern Irish, no religion, School E).

These views contrasted sharply with those rehearsed by students in the separate schools. Here there is an acceptance of separation and a consciousness of the deep cleavages between the social and political aspirations of the groups. There is also a notable omission of any reference to the separate school system and the impact this might have upon identity and concomitant intergroup relations. So whilst a minority acknowledge the importance of improving relations, the general consensus is of an ongoing identity-based political struggle as is illustrated below:

The Queen has a nerve to come over and visit the South while there is still a political war going on in the North (Irish Catholic, School B)

The civil war that is still going on is about land (Irish Catholic, School B)

A cursory glance at the data above might offer support to the arguments advanced earlier by Strike, Judge and Pring: The integrated school presents a more conducive space for fostering tolerance and positive intergroup relations than the separate school. Participants are more 'moderate' in their responses and try to lend emphasis to what the groups have in common rather than focusing on their differences. Yet closer engagement with the data suggests that the issues are more complex than this initial analysis might allow. Research undertaken by Jackman and Crane (1986) for example cast doubt on the assumption that contact will challenge divisions and, aspects of their critique are exemplified in the data above. Of particular note is their argument that contact 
contributes to the idea that acts of prejudice are psychologically rather than politically derived and so are the preserve of the ignorant rather than the disadvantaged. The participants of the integrated school seem to harbour similar perspectives, yet, interestingly, participants deem themselves to have been 'cured' of their ignorance and this is largely measured by their realisation that they are essentially the same as the 'other'. Moreover, that many of those in the integrated school expressed a sense of shame and a desire to leave their country suggests a lack of motivation to change or challenge a political situation which clearly frustrates them. Thus, and as Dixon et al (2012) contend building positive relations can paradoxically obstruct measures to build a more equal society:

[Building positive relations]...may have ironic effects on the political attitudes of the historically disadvantaged, decreasing their perceptions of injustice and willingness to engage in collective action to transform social inequalities (411);

An appreciation of the institutional bases of conflict however is constantly apparent within the data from the separate schools. Both Catholic and Protestant pupils continue to express concern about the injustices visited upon their group by the state. In contrast to those in the integrated school though there is little evidence that they see making friends with the 'other' as the key solution. Rather the conflict is framed in terms of political and state injustice and so the solution will naturally be found in the revision of political structures. However the adequacy of such assessments has been questioned by conflict theorists. Lederach (2003) in his discussions of conflict transformation explains that conflict is inherently multi-faceted and any attempt to transform it must appreciate its complexity and seek to produce change within each of its dimensions: 
[Conflict] Transformation understands social conflict as evolving from, and producing changes in, the personal, relational, structural and cultural dimensions of human experience. It seeks to promote constructive processes within each of these dimensions (2)

Yet the discourse around identity and the narratives of the conflict presented across the school types in this paper are limited and this potentially raises questions about the socially transformative potential of separate or integrated schools.

\section{Conclusion}

The purpose of this paper was to explore how identity is interpreted by school children across different school types in Northern Ireland and how children in different school types are positioned towards the 'other' identity. Drawing on the content of essays entitled 'my country' it was shown that children across Catholic, Protestant and mixed contexts construct and interpret identity differently. Children within the separate school types tend to readily identify on the basis of traditional allegiances as was also evident in Murray's research in 1985. However, and reflecting work by Schubotz and Devine (2005), Hayes et al (2007) and the 2011 census data, it is also clear that Northern Irish is beginning to be employed as an identity descriptor although this is used more often by children in the integrated school. Whilst the qualitative approach employed to collect the data naturally prevents generalisation, and the structure of the Northern Irish education system frustrates efforts to achieve social demographic parallelism between the schools, 
the paper does nonetheless shed light on key issues pertaining to identity, social cohesion and schools that are worth rehearsing below:

Firstly, the paper offers insights into the meaning attached to the 'Northern Irish' identity. Hayes et al (2007) have found that adults who claimed to have had an integrated education were more likely to adopt the argued that the identity 'Northern Irish' identity, is commonly used by pupils in integrated schools and suggested that this trend might provide evidence of greater moderation in attitude. The data here show that this term is also employed by participants across all schools although there was a greater propensity for Protestants than Catholics within separate schools to assert Northern Irish identification. However what is perhaps more important is that the term was defined differently by children across the different school types. Thus when it was employed within the separate school context, there was little evidence to signify that it was adopted on the basis of greater inclusiveness. Whilst fewer Catholics used this identity classification, Protestants in Protestant schools who defined themselves as Northern Irish constructed identity as oppositional and negatively interdependent. However when employed by children in the integrated school it seemed to reflect a more inclusive sense of self and group.

Secondly, and relatedly, the data reveal the enduring relevance of the Irish or British group identity to young people and the potential importance of school type for reflecting and reproducing these identity classifications. As noted above, a more inclusive interpretation of the Northern Irish identity label is employed within the integrated school; however and resonant with Murray's analysis, both identity groups in the separate schools demonstrated a strong sense of attachment to the traditional Catholic and 
Protestant identity categories. Within the separate school context, identity is imbued with meaning, signified by cognitive, evaluative, and affective identity dimensions. At the same time, analysis indicated differences across identities and groups. Irish identity (favoured by Catholics) is infused with cultural meaning, and pervades most aspects of life. In contrast, there is less consistency surrounding the meaning of British identity (favoured by Protestants), which is typically represented as pertaining to British symbolism. This finding corresponds with earlier research on religious and national identity that suggests, for Protestants, the British identity is associated with greater ambiguity compared with the Irish identity for Catholics (Muldoon et al., 2007). Irrespective of this difference, for both groups, identification is coupled with high levels of interactional and affective commitment. In relation to the former, social ties were highlighted as constituting an important aspect of identity. Surprisingly, this aspect of commitment appeared to have greater precedence among the Protestant (mainly British) identifiers. This contradicts previous research indicating greater evidence of interactional commitment among the Catholic (mainly Irish identifiers) community (Cassidy \& Trew, 2004). Importantly however, Cassidy and Trew (2004) reported this finding in relation to religious as opposed to national identity, and attributed it to the more individualistic orientation associated with Protestantism. At the same time, they did acknowledge the capacity of certain contexts, such as the marching season, to prompt collectivist perceptions. If this is the case, then arguably, the recent flag dispute might go some way to explaining the higher levels of interactional commitment among this group. They simply do so to a greater or lesser extent depending on the specific dimension of group commitment.

Finally, the data offers insights into the way in which pupils perceive the 'other' across each of the school types. As noted earlier, Strike and Judge have emphasised the value of 
mixed group contexts for challenging division and conflict. The data, as indicated above, offer some support to this argument in so far as the young people in the integrated context are likely to construct their identity in more inclusive ways than those in the separate schools where there was a stronger attachment to traditional identity categorisations, and a tendency to be negatively pre-disposed towards the 'other' identity group. Moreover, there was evidence that those within the integrated school were more willing to engage in objective discussions of identity and this may suggest their capacity to more easily empathise and engage with the struggles experienced by the other group. However closer inspection of the data from pupils in the integrated school cast light on the process of othering'. Specifically the data from this school suggests that othering is not a process confined just to separate schools. Rather the 'other' is just constructed differently within the integrated school and is characterised chiefly by those who lack the 'intelligence' to move beyond identity based struggle. This is an important finding because it illustrates something of the limitations of intergroup contact for facilitating participants to see division as anything more than a problem of intolerance that is the preserve of those who lack the emotional and intellectual sophistication to 'move on'. But more importantly it also suggests a limited awareness of the processes of social disadvantage that fuel division and conflict (Dixon et al, 2005; Dixon et al, 2012). Thus if the content of students' writing is resonant with the cultures embedded within each of the school types, it is difficult to see that one school type has the monopoly on promoting cohesion; rather each, in its own way, appears to impart partial constructions of division that require deconstruction and challenge (Lederach, 2003). 


\section{References}

Akenson, DH (1973) Education and Enmity: The Control of Schooling. Northern Ireland 1920-1950 (David and Charles Ltd).

Ashmore, R. D., Deaux, K., \& McLaughlin-Volpe, T. (2004) An organizing framework for collective identity: articulation and significance of multidimensionality, Psychological bulletin, 130(1), 80.

Bain, G. (2006) Schools for the Future: Funding, Strategy (Sharing Report of the Independent Strategic Review of Education).

Buckland, P. (1979) The Factory of Grievances: devolved government in Northern Ireland (Dublin, 1979). 
Bull, P. (2006). Shifting patterns of social identity in Northern Ireland. PSYCHOLOGISTLEICESTER-, 19(1), 40-43.Cairns, E. (1982) Intergroup conflict in Northern Ireland, in: H. Tajfel (Ed) Social identity and intergroup relations (pp. 277-297) (Cambridge, Cambridge University Press).

Cassidy, C., \& Trew, K. (1998) Identities in Northern Ireland: A multidimensional approach, Journal of Social Issues, 54(4), 725-740.

Cassidy, C., \& Trew, K. (2004) Identity change in Northern Ireland: A longitudinal study of students' transition to university, Journal of Social Issues, 60(3), 523-540.

Deaux, K. (1996) Social identification, in: E. T. Higgins \& A. W. Kruglanski (Eds) Social Psychology: Handbook of basic principles (pp. 777-798) (New York: Guilford).

Dey, I. (1993) Creating categories: Qualitative data analysis, 94-112 (Routledge).

Dixon, J; Durrheim, K., \& Tredoux, C (2005). Beyond the Optimal Contact Strategy A Reality Check for the Contact Hypothesis, American Psychologist, 60, 7, 697-711.

Dixon, J., Levine M., Reicher, S., \& Durrheim, K. (2012) Beyond prejudice: are negative evaluations the problem and is getting us to like one another more the solution? Behaviour Brain Science, 35(6):411-25.

Doosje, B., \& Ellemers, N. (1997) Stereotyping under threat: The role of group identification, in: R. Spears, P. J Oakes, N. Ellemers \& S. A. Haslam (Eds) The social psychology of stereotyping and group life (pp. 257-272) (Oxford, Blackwell).

Dunn, S., \& Morgan, V. (1999) 'A Fraught Path'-education as a basis for developing improved community relations in Northern Ireland, Oxford review of education, 25(1-2), 141-153.

Durkheim, E. (1956) Education and sociology (Simon and Schuster). 
Elizabeth, V. (2008) Another String to Our Bow: Participant Writing as Research Method, Forum Qualitative Social Research Volume 9, No. 1, Art. 31 - January.

Ellemers, N., Kortekaas, P., \& Ouwerkerk, J. W. (1999) Self-categorisation, commitment to the group and group self-esteem as related but distinct aspects of social identity, European journal of social psychology, 29(2-3), 371-389.

Emler, N., \& Hopkins, N. (1990) Reputation, social identity and the self. Social identity theory: Constructive and critical advances, 113-130 (New York, Springer-Verlag).

Ethier, K. A., \& Deaux, K. (1994) Negotiating social identity when contexts change: Maintaining identification and responding to threat, Journal of personality and social psychology, 67(2), 243.

Fahey, T., Hayes, B. C., \& Sinnott, R. (2005). Conflict and consensus: A study of values and attitudes in the Republic of Ireland and Northern Ireland. Institute of public administration.Finlay, A. (2001) Defeatism and northern Protestant 'identity', The Global Review of Ethnopolitics, 1(2), 3-20.

Firestone, W. A. (1987) Meaning in method: The rhetoric of quantitative and qualitative research, Educational researcher, 16(7), 16-21.

Halstead, M. \& McLaughlin, TJ. (2005) Are faith schools divisive?, in: R. Gardner, J. Cairns \& D. Lawton (Eds) Faith schools consensus and Conflict (pp61-73) (RoutledgeFalmer).

Hayes, B. C., McAllister, I., \& Dowds, L. (2007) Integrated Education, Intergroup Relations, and Political Identities in Northern Ireland, Social Problems Vol. 54, Issue 4, pp. 454-482.

Glaser, B. G., \& Strauss, A. L. (1967) The discovery of grounded theory: Strategies for qualitative research (New York: Aldine). 
Goetz, J. P., \& LeCompte, M. D. (1981) Ethnographic research and the problem of Data Reduction1, Anthropology \& Education Quarterly, 12(1), 51-70.

Irish News (October 21, 2014) Catholic school chiefs say: stop promoting integrated education.

Jackman, M. R., \& Crane, M. (1986) “Some of my best friends are Black . ..": Interracial friendship and Whites' racial attitudes, Public Opinion Quarterly, 50, 459-486.

Jackson, S. E. (1981) Measurement of commitment to role identities, Journal of Personality and Social Psychology, 40(1), 138.

Jackson, J. W., \& Smith, E. R. (1999) Conceptualizing social identity: A new framework and evidence for the impact of different dimensions, Personality and Social Psychology Bulletin, 25(1), 120-135.

Judge, H. (2001) Faith-based Schools and State Funding: A partial argument, Oxford Review of Education Vol. 27, No. 4.

Lederach, JP. (2003) Beyond intractability Conflict Transformation, (http://www.beyondintractability.org/about/citing-beyond-intractabilityresources accessed October 2014)

Levinson, M. (2007) “Common Schools and Multicultural Education", Journal of Philosophy of Education 41(4): 625-42.

Maykut, P. S., \& Morehouse, R. E. (1994) Beginning qualitative research: A philosophic and practical guide (Vol. 6) (London, Falmer Press).

McGlynn, C., Niens, U., Cairns, E., \& Hewstone, M. (2004) Moving out of conflict: the contribution of integrated schools in Northern Ireland to identity, attitudes, forgiveness and reconciliation, Journal of Peace Education, 1, 147163. 
Muldoon, O. T., Trew, K., Todd, J., Rougier, N., \& McLaughlin, K. (2007) Religious and national identity after the Belfast Good Friday Agreement, Political Psychology, 28(1), 89-103.

Mummendey, A., Klink, A., \& Brown, R. (2001) Nationalism and patriotism: National identification and out-group rejection, British Journal of Social Psychology, 40(2), $159-172$.

Murray, D. (1985) Worlds Apart: Segregated Schools in Northern Ireland (Appletree Press).

Northern Ireland Statistics and Research Agency, 2011 Census:. Downloaded from: http://www.nisra.gov.uk/Census.html

Patton, M. Q. (1990) Qualitative evaluation and research methods (SAGE Publications, inc).

Pring, R. (2005) Faith Schools: can they be justified? in: R. Gardner, J. Cairns \& D. Lawton (Eds) Faith schools consensus and Conflict (pp51-60) (Routledge-Falmer).

Shaver, P., Schwartz, J., Kirson, D., \& O'connor, C. (1987) Emotion knowledge: further exploration of a prototype approach, Journal of personality and social psychology, 52(6), 1061.

Schubotz, D., \& Devine, P. (2005). What now? Exploring community relations among 16-year olds in Northern Ireland. Shared Space, Jg, 1, 53-70.Strike, K. (2001) Civil Society and Schooling: particularistic voices and public spaces, in: Heinz-Dieter Meyer, William Lowe Boyd (Eds) Education Between Stedate, Markets, and Civil Society: Comparative Perspectives (New Jersey: Taylor and Francis).

Stryker, S., \& Serpe, R. T. (1982) Commitment, identity salience, and role behavior: Theory and research example, in: Personality, roles, and social behavior (pp. 199-218) (Springer, New York). 
Tajfel, H. (1978) (Ed) Differentiation between social groups: Studies in the psychology of intergroup relations (London, Academic Press).

Trew, K., \& Benson, D. E. (1996) Dimensions of social identity in Northern Ireland, Changing European identities: Social-psychological analyses of social change, 123-143.

Trew, K, Cox, C and Ward, P. (1995). Dimensions of Social Identity in Northern Ireland. Report.Turner, J. C. (1982) Towards a cognitive redefinition of the social group, in: H. Tajfel (Ed) Social identity and intergroup relations, 15-40 (Cambridge, Cambridge University Press).

Waddell, N. (1988) Situational determinants of social identity salience in Northern Ireland, Unpublished doctoral dissertation (University of Ulster, Coleraine).

Waddell, N., \& Cairns, E. (1986) Identity preference in Northern Ireland, Political Psychology, 12, 2, 205-213.

Table 1

The breakdown of school type, the number of students per school category, and the distribution of Catholic and Protestant students in the various school categories.

\begin{tabular}{|lccc|}
\hline School Type & $\boldsymbol{n}$ & Catholics (\%) & Protestants (\%) \\
\hline Catholic Maintained Secondary & 17 & $88 \%$ & ---- \\
Catholic Maintained Grammar & 83 & $84 \%$ & --- \\
Protestant Controlled Secondary & 56 & $75 \%$ & $4 \%$ \\
Protestant Controlled Grammar & 45 & $78 \%$ & --- \\
Integrated School & 64 & $50 \%$ & $27 \%$ \\
\hline
\end{tabular}


Note Remaining percentage in each school category answered either 'Neither Catholic or Protestant' or 'Not sure'.

$n=$ Number of total participants per school type category 